\title{
Novel Biocompatible Nanoreactor for Silica/Gold Hybrid Nanoparticles Preparation
}

\author{
Md. Amran Hossain ${ }^{1}$, Yutaka Ikeda ${ }^{1}$, Toru Hara ${ }^{2}$ and Yukio Nagasaki ${ }^{1,3,4^{*}}$
}

${ }^{1}$ Graduate School of Pure and Applied Sciences, University of Tsukuba, Ten-noudai 1-1-1, Tsukuba, Ibaraki 305-8573, Japan

${ }^{2}$ National Institute for Materials Science, 1-1 Namiki, Tsukuba, Ibaraki 3050044, Japan

${ }^{3}$ Master's School of Medical Sciences, University of Tsukuba, Ten-noudai 1-1-1, Tsukuba, Ibaraki 305-8573, Japan

${ }^{4}$ Satellite Laboratory of International Center for Materials Nanoarchitechtonics (WPI-MANA), National Institute of Materials Science(NIMS), Ten-noudai 1-1-1, Tsukuba, Ibaraki 305-8573, Japan

yukio@nagalabo.jp 


\begin{abstract}
A new approach to the preparation of PEGylated [PEG: poly(ethylene glycol)] $\mathrm{SiO}_{2} / \mathrm{Au}$ hybrid nanoparticles was investigated. The synthesis of a PEGylated nanogel containing $\mathrm{SiO}_{2} / \mathrm{Au}$ hybrid nanoparticles was performed using matrixcatalyzed hydrolysis of tetraethyl orthosilicate, followed by the reduction of $\mathrm{HAuCl}_{4}$. UV-vis absorption of the prepared hybrid particles was obtained at $618 \mathrm{~nm}$, which is a much longer wavelength than that of a nanogel containing only Au nanoparticles $(523 \mathrm{~nm})$. High-angle annular dark field images of the prepared particles observed using transmission electron microscopy and energy-dispersive X-ray spectroscopy confirmed the coexistence of Si and Au in the same particle. The presence of $\mathrm{Si}$ and $\mathrm{Au}$ in the prepared particles was also confirmed by inductively coupled plasma atomic emission spectroscopy. Dynamic light-scattering measurements of the particles in a highly ionic medium showed that they have high stability in both acidic and basic regions.
\end{abstract}

\title{
Keywords: $\mathrm{SiO}_{2} / \mathrm{Au}$ hybrid nanoparticle, PEGylated nanogel, Nanoreactor, Bioimaging
}

\section{Introduction}

Nanoparticles have been extensively investigated during the last few decades because of their unique properties and potential applications. In recent years, metal nanoparticles such as $\mathrm{Au}[1,2], \mathrm{Ag}[3,4], \mathrm{Pt}[5,6]$, and Fe oxide [7, 8] nanoparticles have attracted widespread interest in biomedical applications, including disease diagnosis and treatments. They have unique mechanical, electronic, magnetic, optical, and chemical properties. More recently, hybrid nanoparticles composed of metals and dielectric materials (usually $\mathrm{SiO}_{2}$ ) have been shown to have potential applications in biomedical areas. The hybrid nanoparticles can exhibit a strong optical resonance at a much longer wavelength than the corresponding optical resonance of metal nanoparticles. In particular, new hybrid nanocomposites consisting of dielectric $\mathrm{SiO}{ }_{2}$ and $\mathrm{Au}$ show strong optical resonance in a wide region (from visible to near-infrared) of the electromagnetic spectrum [9-11]. This property makes them promising building blocks with many biomedical applications, such as in biological imaging [12, 13], thermal ablative cancer therapy $[14,15]$, immunoassays, and photothermally activated drug delivery $[16]$. These $\mathrm{SiO}_{2} / \mathrm{Au}$ hybrid particles are biologically inert [17] and have low toxicity [18]. However, the $\mathrm{SiO}_{2} / \mathrm{Au}$ particles are unstable in physiological environments, so their stabilities need to be increased for in vivo applications. As a result of the steric 
stabilization and stealth properties of poly(ethylene glycol) (PEG), PEGylation of $\mathrm{SiO}_{2} / \mathrm{Au}$ hybrid nanoparticles is widely used to make the particles suitable for in vivo applications [19-21]. However, PEGylation of nanoparticles by mono-endfunctionalized PEG often causes de-PEGylation under physiological conditions [22], resulting in aggregation of the particles.

We previously reported that a PEGylated nanogel composed of a cross-linked poly[2-( $N, N$-diethylamino)ethyl methacrylate] (PEAMA) core and a tethered PEG shell [23] acts as a nanoreactor as well as a stabilizer for Au nanoparticles by autoreduction of chloroaurate ions within the cross-linked PEAMA core [24]. Coordination of the amino lone-pair of the PEAMA chain effectively stabilizes the Au nanoparticles in the nanogel. The PEGylated nanogel shows high stability against extremely dilute and high salt conditions, excellent biocompatibility, negligible toxicity, and prolonged blood circulation [25]. The nanogel also shows significant volume phase transitions (swelling/deswelling) in response to $\mathrm{pH}$ changes $[23,26]$. Accordingly, if other metal nanoparticles are prepared by template preparation inside nanogels, the range of in vivo applications of PEGylated nanogels for the diagnostic and disease treatments will be further expanded. In this report, we describe a simple method for the synthesis of $\mathrm{SiO}_{2} / \mathrm{Au}$ hybrid nanoparticles by matrix-catalyzed hydrolysis of tetraethyl orthosilicate (TEOS), followed by the reduction of $\mathrm{HAuCl}_{4}$ in presence of PEGylated polyamine nanogel. $\mathrm{SiO}_{2} / \mathrm{Au}$ hybrid nanoparticles were obtained in the nanogel core. The surface plasmon band of the obtained hybrid particles was observed at a longer wavelength $(618 \mathrm{~nm})$ than that of a PEGylated nanogel containing Au nanoparticles $(523 \mathrm{~nm})$ under specific conditions, and the prepared PEGylated nanogel containing $\mathrm{SiO}_{2} / \mathrm{Au}$ nanoparticles showed excellent stability under physiological conditions.

\section{Experimental}

\subsection{Materials}

Ethylene glycol dimethacrylate (EGDMA; Wako, Tokyo, Japan) and 2-(N,N-diethylamino)ethyl methacrylate (EAMA, Wako) were distilled over $\mathrm{CaH}_{2}$ under reduced pressure. The PEG macromonomer (acetal-PEG-PhCH=CH $\mathrm{CH}_{2} ; M_{\mathrm{n}}=$ 6300) was synthesized according to our previous report [23]. Potassium persulfate (KPS; Wako) was purified by recrystallization from water and then dried in vacuo. TEOS (Sigma-Aldrich, St. Louis, MO, U.S.A.) and tetrachloroauric acid $\left(\mathrm{HAuCl}_{4}\right.$; Sigma-Aldrich) were used without further purification. Water was purified using a Milli-Q system (Millipore, 
Molsheim, France).

2.2 Synthesis of PEGylated nanogel containing $\mathrm{SiO}_{2}$ nanoparticles $\left(\mathrm{SiO}_{2} \mathrm{NG}\right)$

The nanogel was prepared as previously described [23]; briefly, EAMA was emulsion polymerized with EGDMA ( $3 \mathrm{~mol} \%$ ) in the presence of acetal-PEG- $\mathrm{PhCH}=\mathrm{CH}_{2}$, which acts as both an emulsifier and a comonomer. KPS was used as an initiator. The copolymerization was carried out at room temperature for $24 \mathrm{~h}$. In a typical procedure for the preparation of the pH-responsive PEGylated $\mathrm{SiO}_{2} \mathrm{NGs}$ at $\mathrm{N} / \mathrm{Si}$ ratios of $1,0.5,0.2$, and $0.1,20 \mathrm{mg}$ of nanogel in $1 \mathrm{~mL}$ of $\mathrm{H}_{2} \mathrm{O}([\mathrm{N}]=38$ $\mu \mathrm{mol})$ were put in a glass vial and the vial was placed on a magnetic stirrer at $350 \mathrm{rpm}$. The desired amount of TEOS ([Si] $=$ $38,76,190$, and $380 \mu \mathrm{mol}$ ) was added and the reaction mixture was stirred for $24 \mathrm{~h}$ at room temperature. The prepared $\mathrm{SiO}_{2} \mathrm{NG}$ was purified by dialysis against $2 \mathrm{~L}$ of water for $2 \mathrm{~d}$ (the water was changed after 1, 2, 4, 8, 12, and $24 \mathrm{~h}$ ) using a membrane with a molecular weight cutoff size of 1 million. A blank experiment was performed in order to check the

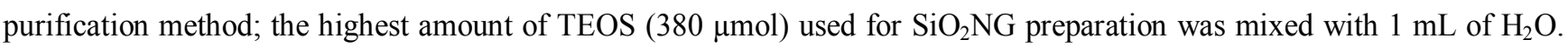
After $24 \mathrm{~h}$ of stirring, the mixture was purified by dialysis as in the $\mathrm{SiO}_{2} \mathrm{NG}$ purification.

2.3 Synthesis of PEGylated nanogel containing $\mathrm{SiO}_{2} / \mathrm{Au}$ hybrid nanoparticles $\left(\mathrm{SiO}_{2} / \mathrm{AuNG}\right)$

For the synthesis of the PEGylated nanogel containing $\mathrm{SiO}_{2} / \mathrm{Au}$ hybrid nanoparticles, $5 \mathrm{mg}(1 \mathrm{~mL})$ of the prepared $\mathrm{SiO}_{2} \mathrm{NG}$ (Table1; Run-2) were placed in a glass vial and the $\mathrm{pH}$ was adjusted to 9.0 by adding $1 \mathrm{~mL}$ of $0.01 \mathrm{M}$ tetraborate buffer. Then $4 \mathrm{mg}$ (in $1 \mathrm{~mL}$ of $\mathrm{H}_{2} \mathrm{O}$ ) of $\mathrm{HAuCl}_{4}$ were added and the resulting mixture was stirred for $24 \mathrm{~h}$ at room temperature. The prepared particles were purified by dialysis against $2 \mathrm{~L}$ of water for $2 \mathrm{~d}$ (the water was changed after 1,2, $4,8,12$, and $24 \mathrm{~h}$ ) using a membrane with a molecular weight cutoff size of 1 million. A blank experiment was performed in order to check the purification method; $4 \mathrm{mg}$ (in $1 \mathrm{~mL}$ of $\mathrm{H}_{2} \mathrm{O}$ ) of $\mathrm{HAuCl}_{4}$ were mixed with $1 \mathrm{~mL}$ each of $\mathrm{H}_{2} \mathrm{O}$ and tetraborate buffer (0.01 M; pH 9.0). After stirring for $24 \mathrm{~h}$, the mixture was purified by dialysis using the same method as for the $\mathrm{SiO}_{2} / \mathrm{AuNG}$ purification.

\subsection{Characterization}


The particle sizes of the $\mathrm{SiO}_{2} \mathrm{NG}$ and PEGylated nanogel containing $\mathrm{SiO}_{2} / \mathrm{Au}$ nanoparticles were evaluated by dynamic light-scattering (DLS) using a Zetasizer Nano ZS (Malvern Instruments, Ltd., Malvern, U.K.) equipped with a 4$\mathrm{mW}$ He-Ne ion laser $(\lambda=633 \mathrm{~nm})$. The DLS measurements were carried out at $37.0^{\circ} \mathrm{C}$ at a detection angle of $173^{\circ}$. To determine the amount of Si immobilized in the $\mathrm{pH}$-responsive PEGylated nanogels, inductively coupled plasma atomic emission spectroscopy (ICP-AES) analysis of the $\mathrm{SiO}_{2} \mathrm{NG}$ was carried out using a Shimadzu (Kyoto, Japan) ICPS-8100 plasma emission spectrometer. To characterize the optical properties of the $\mathrm{SiO}_{2} \mathrm{NG}$ and the pH-responsive nanogel containing $\mathrm{SiO}_{2} / \mathrm{Au}$ nanoparticles, UV-vis spectra were recorded using Thermo Scientific (Waltham, MA, U.S.A.) SkanIt ${ }^{\circledR}$ Software for a Varioskan ${ }^{\circledR}$ Flash version 2.4.3 spectrometer. Transmission electron microscope (TEM) samples were prepared by mounting a drop of the solution on a carbon-coated $\mathrm{Cu}$ grid and allowing it to dry in air. TEM analysis of the $\mathrm{SiO}_{2} \mathrm{NG}$ was carried out using a JEOL (Tokyo, Japan) JEM-1400 instrument operated at $80 \mathrm{kV}$. For the $\mathrm{SiO}_{2} / \mathrm{AuNG}$ sample, TEM analysis was carried out using a JEOL JEM-2010F instrument equipped with an energy-dispersive X-ray spectrometer (EDS; BRUKER XFlash 5030, Berlin, Germany) operating at $200 \mathrm{kV}$.

\section{Results and discussion}

A schematic diagram of the synthesis of the $\mathrm{SiO}_{2} / \mathrm{Au}$ hybrid nanoparticles inside the pH-responsive PEGylated nanogel is shown in Figure 1. First, a PEGylated nanogel containing $\mathrm{SiO}_{2}$ nanoparticles $\left(\mathrm{SiO}_{2} \mathrm{NG}\right)$ was prepared by hydrolysis of TEOS by the polyamine core of the PEGylated nanogel. The prepared $\mathrm{SiO}_{2} \mathrm{NG}$ was purified by dialysis against water using a membrane with a molecular weight cutoff size of 1 million. To check the purification efficiency, a blank experiment was performed, as described in the experimental section. Elemental analysis using ICP-AES of the blank sample after dialysis does not show any Si (Table S1 in the Supporting Information), confirming the successful purification of the prepared $\mathrm{SiO}_{2} \mathrm{NG}$ by dialysis. After purification of the prepared $\mathrm{SiO}_{2} \mathrm{NG}$, the amount of $\mathrm{Si}$ was analyzed using ICPAES. The quantitative data are summarized in Table 1. Note that the amount of immobilized Si increased with decreasing $\mathrm{N} / \mathrm{Si}$ ratio (increasing amount of TEOS) and it becomes constant after the N/Si ratio reaches 0.2. 
The $\mathrm{SiO}_{2} \mathrm{NG}$ was also analyzed by TEM, as shown in Figure 2. Some smaller and high contrast particles can be seen in the nanogel, which were detected as higher and lower contrast particles in the image, suggesting the formation of $\mathrm{SiO}_{2}$ particles in the nanogel core. The size of the $\mathrm{SiO}_{2}$ nanoparticles is about $18 \mathrm{~nm}$.

Secondly, $\mathrm{SiO}_{2} / \mathrm{Au}$ hybrid particles were prepared in the nanogel core. We have previously reported that amino groups in a nanogel core reduce aurate cations effectively to form Au nanoparticles in the nanogel [24]. If the amineassisted aurate reduction takes place in the $\mathrm{SiO}_{2} \mathrm{NG}$ as it does in the $\mathrm{NG}$, it is anticipated that a new $\mathrm{SiO}_{2} / \mathrm{Au}$ hybrid will be formed in the nanogel. The reduction of aurate ions was examined by simple addition of $\mathrm{HAuCl}_{4}$ to a previously prepared $\mathrm{SiO}_{2} \mathrm{NG}$ at various $\mathrm{pH}$ values. After the reaction, the reaction mixture was dialyzed against water and the amount of $\mathrm{Au}$ in $\mathrm{SiO}_{2} \mathrm{NG}$ was determined from ICP-AES analysis, as shown in Table 2. The obtained data confirm the presence of Au in the prepared particles. The purification efficiency was also checked by elemental analysis of a blank sample by ICP-AES. The preparation of the blank sample is described in the experimental section. The analysis results (See Table S2 in the Supporting Information) confirm that there is no Au present in the blank sample after dialysis.

Figure 3 shows the UV-vis spectra of the PEGylated nanogel containing $\mathrm{SiO}_{2} / \mathrm{Au}$ hybrid particles prepared at various $\mathrm{pH}$ values. A typical absorption based on the plasmon band of the Au surface was observed at around $520 \mathrm{~nm}$ for most of the samples. It is interesting to note that the absorption was observed at a much longer wavelength (618 $\mathrm{nm})$ for the sample prepared at $\mathrm{pH} 9.0$, suggesting the formation of $\mathrm{SiO}_{2} / \mathrm{Au}$ hybrid particles. The changes in the $\mathrm{UV}$-vis spectra of the particles as a function of time are shown in Figure 4. The $\lambda_{\max }$ of the particles was observed at around $540 \mathrm{~nm}$ initially, suggesting the formation of primary Au particles [27] from the reduction of Au (III) ions by the polyamine core of the nanogel. The $\lambda_{\max }$ changed to $618 \mathrm{~nm}$ after $40 \mathrm{~min}$ in the case of the particles prepared at $\mathrm{pH} 9.0$ [Figure 4(a)]. This observation suggests that after formation, the primary Au particles interacted with the $\mathrm{SiO}_{2}$ particles and formed stable $\mathrm{SiO}_{2} / \mathrm{Au}$ hybrid particles in the nanogel core. In contrast, the $\lambda_{\max }$ values of the particles prepared at neutral or acidic pHs [Figure 4(b)] gradually shifted to $520 \mathrm{~nm}$ with time, suggesting the formation of stable Au nanoparticles through the ionexchange reaction between protonated amino group of the nanogel core $\left(-\mathrm{N}^{+} \mathrm{Me}_{2} \mathrm{HCl}^{-}\right)$and the $\mathrm{AuCl}_{4}{ }^{-} \mathrm{H}^{+}$, followed by the reduction of aurate ions by the polyamine core [24].

A high-angle annular dark field TEM image of the PEGylated nanogel containing $\mathrm{SiO}_{2} / \mathrm{Au}$ hybrid particles is shown in Figure 5(a). The $\mathrm{SiO}_{2} / \mathrm{Au}$ hybrid particles (brighter particles) are clearly observed in the nanogel (low contrast 
particles). The EDS spectra [Figure 5(b)] highlighted the brighter particles (indicated by “+”) in Figure 5(a), showing the presence of both $\mathrm{Si}$ and $\mathrm{Au}$ in the same particle; this observation confirmed the formation of $\mathrm{SiO}_{2} / \mathrm{Au}$ hybrid particles in the nanogel core. On the basis of these results, viz., the UV-vis and the EDX data, it is concluded that $\mathrm{Au} / \mathrm{SiO}_{2}$ hybrid was truly formed in the core of nanogel.

The size distributions of the PEGylated nanogels containing $\mathrm{SiO}_{2} / \mathrm{Au}$ hybrid particles at different $\mathrm{pH}$ values, measured using DLS, are shown in Figure 6. Measurements carried out in water containing $0.15 \mathrm{M} \mathrm{NaCl}$ at $37^{\circ} \mathrm{C}$ showed a unimodal size distribution [polydispersity index $(\mathrm{PDI})<0.15$ ] under both acidic and basic $\mathrm{pH}$ conditions; this indicates high stability of the particles in high ionic strength environments over a wide $\mathrm{pH}$ range. Because the nanogel has amino groups in its core, it shows $\mathrm{pH}-\mathrm{dependent}$ volume phase transitions $[23,26]$. This phenomenon is very useful in biomedical applications such as in vivo drug delivery systems [28]. Figure 7 shows the $\mathrm{pH}$ dependence of the diameter of the PEGylated nanogel containing $\mathrm{SiO}_{2} / \mathrm{Au}$ hybrid particles, measured using DLS. The diameter of the PEGylated nanogel containing $\mathrm{SiO}_{2} / \mathrm{Au}$ hybrid particles increased proportionally, with a unimodal size distribution, with decreasing $\mathrm{pH}$, reaching a hydrodynamic volume at $\mathrm{pH}<7.5($ diameter $=137.2 \mathrm{~nm})$; this is 1.4 times that at $\mathrm{pH}>7.5($ diameter $=122.4$ $\mathrm{nm}$ ). This confirmed that the $\mathrm{SiO}_{2} / \mathrm{AuNG}$ also shows volume phase transitions similar to those of the original nanogel, although the degree of swelling was lower than that of the original nanogel as a result of coordination of some of the amino groups on the nanoparticle surfaces.

\section{Conclusions}

In conclusion, the synthesis of a $\mathrm{pH}$-responsive PEGylated nanogel containing $\mathrm{SiO}_{2} / \mathrm{Au}$ hybrid nanoparticles was successfully performed using matrix-catalyzed hydrolysis of TEOS, followed by addition of $\mathrm{HAuCl}_{4}$ at $\mathrm{pH}$ 9.0. The surface plasmon band of the PEGylated nanogel containing $\mathrm{SiO}_{2} / \mathrm{Au}$ hybrid nanoparticles was observed at a longer wavelength than that of a PEGylated nanogel containing Au nanoparticles. TEM-EDS data showed the formation of $\mathrm{SiO}_{2} / \mathrm{Au}$ hybrid particles in the nanogel. The prepared PEGylated nanogel containing $\mathrm{SiO}_{2} / \mathrm{Au}$ hybrid nanoparticles had high stability under physiological conditions, and showed reversible volume phase transitions (swelling) in response to $\mathrm{pH}$. This $\mathrm{pH}-$ responsive PEGylated nanogel containing $\mathrm{SiO}_{2} / \mathrm{Au}$ hybrid nanoparticles may have important applications in biomedical fields. 


\section{Acknowledgement}

A part of this work was supported by the International Center for Materials Nanoarchitectonics (WPI-MANA), National Institute for Materials Science (NIMS), Tsukuba, Japan.

\section{Supporting information}

Elemental analysis data of the blank samples (described in the experimental section) obtained from ICP-AES.

\section{References}

1. Sardar, R.; Funston, A. M.; Mulvaney, P.; Murray R. W. Langmuir 2009, 25(24), 13840.

2. Daniel, M.-C.; Astruc, D. Chem. Rev. 2004, 104, 293.

3. Linkov, I.; Steevens, J. (eds.), Nanomaterials: Risks and Benefits@ Springer Science + Business Media B.V. $2009,287$.

4. Wijnhoven, S. W. P.; Peijnenburg, W. J. G. M.; Herberts, C. A.; Hagens, W. I.; Oomen, A. G.; Heugens, E. H. W.; Roszek, B.; Bisschops, J.; Gosens, I.; Meent, D. V. D.; Dekkers, S.; Jong, W. H. D.; Zijverden, M. V.; Sips, A. J. A. M.; Geertsma, R. E. Nanotoxicology 2009, 3(2), 109.

5. Morales, B. E.; Gamboa, S. A.; Pal, U.; Guardian, R.; Acosta, D.; Magana, C.; Mathew, X. Int. J. Hydrogen Energy 2010, 35, 4215 .

6. Peng, Z.; Yang, H. Nano Today 2009, 4, 143.

7. Weinstein, J. S.; Varallyay, C. G.; Dosa, E.; Gahramanov, S.; Hamilton, B.; Rooney, W. D.; Muldoon, L. L.; Neuwelt, E. A. J. Cerebral Blood Flow Metab. 2010, 30, 15.

8. Jain, T. K.; Morales, M. A.; Sahoo, S. K.; Leslie-Pelecky, D. L.; Labhasetwar, V. Mol. Pharmaceutics 2005 2(3), 194.

9. Yan, S.; Wang, Y.; Wen, T.; Zhu, J. Physica E 2006, 33, 139.

10. Shi, W.; Sahoo, Y.; Swihart, M. T.; Prasad, P. N. Langmuir 2005, 21, 1610. 
11. Lu, Q.; Yao, K.; Xi, D.; Liu, Z.; Luo, X.; Ning, Q. J. Mater. Sci. Technol. 2007, 23, 189.

12. Lee, T. M.; Oldenburg, A. L.; Sitafalwalla, S.; Marks, D. L.; Luo, W. Opt. Lett. 2003, 28, 1546.

13. Kim, J.; Park, S.; Lee, J. E.; Jin, S. M.; Lee, J. H.; Lee, I. S.; Yang, I.; Kim, J. S.; Kim, S. K.; Cho, M. H. Angew. Chem., Int. Ed. 2006, 45, 1.

14. O’Neal, D. P.; Hirsch, L. R.; Halas, N. J.; Payne, J. D.; West, J. L. Cancer Lett. 2004, 209, 171.

15. Lin, A. W. H.; Lweinski, N. A.; West, J. L. J. Biomed. Opt. 2005, 10, 064035.

16. James, W. D.; Hirsch, L. R.; West, J. L.; O'Neal, P. D.; Payne, J. D. J. Radioanal. Nucl. Chem. 2007, $271,455$.

17. Tang, L.; Liu, L.; Elwing, H. B. J. Biomed. Mater. Res. 1998, 41(2), 333.

18. Park, M.-Y.; Lim, S.; Lee, S.-W.; Park, S.-E. Macromol. Res. 2009, 17(5), 307.

19. O'Neal, P. D.; Hirsch, L. R.; Halas, N. J.; Payne, J. D.; West, J. L. Cancer Lett. 2004, 209, 171.

20. Lowery, A. R.; Gobin, A. M.; Day, E. S.; Halas, N. J.; West, J. L. Int. J. Nanomed. 2006, 1(2), 149.

21. Puvanakrishnan, P.; Park, J.; Diagaradjane, P.; Schwartz, J. A.; Coleman, C. L.; Gill-Sharp, K. L.; Sang, K. L.; Payne, J. D.; Krishnan, S.; Tunnell, J. W. J. Biomed. Opt. 2009, 14(2), 024044.

22. Kamimura, M.; Kanayama, N.; Tokuzen, K.; Soga, K.; Nagasaki, Y. Nanoscale, 2011, 3, 3705.

23. Hayashi, H.;Iijima, M.; Kataoka, K.; Nagasaki, Y.Macromolecules 2004, 37, 5389.

24. Oishi, M.; Hayashi, H.; Uno, T.; Ishii, T.; Iijima, M.; Nagasaki, Y. Macromol. Chem. Phys. 2007, 208, 1176.

25. Tamura, M.; Ichinohe, S.; Tamura, A.; Ikeda, Y.; Nagasaki, Y. ActaBiomater. 2011, 7(9), 3354.

26. Oishi, M.; Nagasaki, Y. Nanomedicine, 2010, 5(3), 451.

27. Ji, X.; Song, X.; Li, J.; Bai, Y.; Yang, W.; Peng, X. J. Am. Chem. Soc. 2007, 129, 13939.

28. Oishi, M.; Hayashi, H.; Iijima, M.; Nagasaki, Y J. Mater. Chem., 2007, 17, 3720. 
Table 1:

Analysis of PEGylated nanogel containing $\mathrm{SiO}_{2}$ nanoparticles by ICP-AES.

\begin{tabular}{llccc}
\hline Run & Sample code & $\begin{array}{c}\text { Added } \\
\mathrm{Si}(\mu \mathrm{mol})\end{array}$ & $\begin{array}{c}\mathrm{N} / \mathrm{Si} \\
\text { ratio }\end{array}$ & $\begin{array}{c}\text { Immobilized } \\
\mathrm{Si}(\mu \mathrm{mol})\end{array}$ \\
\hline Run-1 & $\begin{array}{l}\text { PEGylated } \\
\text { Nanogel }\end{array}$ & 0 & - & 0.00 \\
Run-2 & $\mathrm{SiO}_{2} \mathrm{NG}-1$ & 38 & 1 & 5.36 \\
Run-3 & $\mathrm{SiO}_{2} \mathrm{NG}-0.5$ & 76 & 0.5 & 10.36 \\
Run-4 & $\mathrm{SiO}_{2} \mathrm{NG}-0.2$ & 190 & 0.2 & 13.93 \\
Run-5 & $\mathrm{SiO}_{2} \mathrm{NG}-0.1$ & 380 & 0.1 & 13.57 \\
\hline
\end{tabular}

Table 2:

Analysis of PEGylated nanogel containing $\mathrm{SiO}_{2} / \mathrm{Au}$ nanoparticles by ICP-AES.

\begin{tabular}{ccccc}
\hline Run & $\begin{array}{c}\text { Amount of } \\
\mathrm{SiO}_{2} \mathrm{NG}-1(\mathrm{mg})\end{array}$ & $\begin{array}{c}\text { Added } \\
\mathrm{HAuCl}_{4}(\mathrm{mg})\end{array}$ & $\begin{array}{c}\text { Added } \\
\mathrm{Au}(\mu \mathrm{mol})\end{array}$ & $\begin{array}{c}\text { Immobilized } \\
\mathrm{Au}(\mu \mathrm{mol})\end{array}$ \\
\hline Run-1 & & 0 & 0 & 0.00 \\
Run-2 & & 1 & 2.54 & 2.34 \\
Run-3 & 5 & 2 & 5.08 & 4.62 \\
Run-4 & & 3 & 7.61 & 6.60 \\
Run-5 & & 4 & 10.15 & 7.97 \\
\hline
\end{tabular}


Figure 1: Schematic representation of the synthesis of PEGylated nanogel containing $\mathrm{SiO}_{2} / \mathrm{Au}$ hybrid nanoparticles.

Figure 2: TEM photographs of $\mathrm{SiO}_{2} \mathrm{NG}$.

Figure 3: UV-vis absorption spectra of the pH-responsive PEGylated nanogel containing $\mathrm{SiO}_{2} / \mathrm{Au}$ hybrid nanoparticles prepared at various $\mathrm{pH}$ conditions.

Figure 4: UV-vis absorption spectra of the $\mathrm{pH}$-responsive PEGylated nanogel containing $\mathrm{SiO}_{2} / \mathrm{Au}$ hybrid nanoparticles as a function of reaction time; particles prepared at (a) $\mathrm{pH}$ 9.0, (b) $\mathrm{pH} 6.0$.

Figure 5: (a) High angle annular dark field (HAADF) image of PEGylated nanogel containing $\mathrm{SiO}_{2} / \mathrm{Au}$ hybrid particles; (b) EDS spectra of the sample pointed at brighter particles (indicated by “+”) in Figure 5 (a).

Figure 6: Size distribution of the $\mathrm{pH}$-responsive PEGylated nanogel containing $\mathrm{SiO}_{2} / \mathrm{Au}$ hybrid nanoparticles at different $\mathrm{pH}$ conditions, measured by DLS in water containing $0.15 \mathrm{M} \mathrm{NaCl}$ at $37^{\circ} \mathrm{C}$; direction angle, $173^{\circ}$.

Figure 7: $\mathrm{pH}$ dependency of the diameters of the $\mathrm{pH}$-responsive PEGylated nanogel containing $\mathrm{SiO}_{2} / \mathrm{Au}$ hybrid nanoparticles measured by DLS in water containing $0.15 \mathrm{M} \mathrm{NaCl}$ at $37^{\circ} \mathrm{C}$; direction angle, $173^{\circ}$. 
Figure 1:

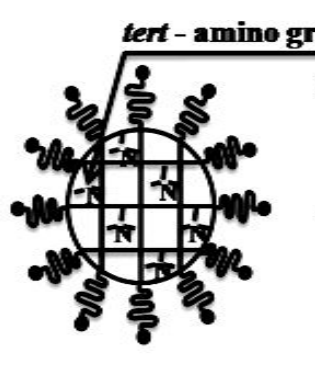

PEGylated nanogel

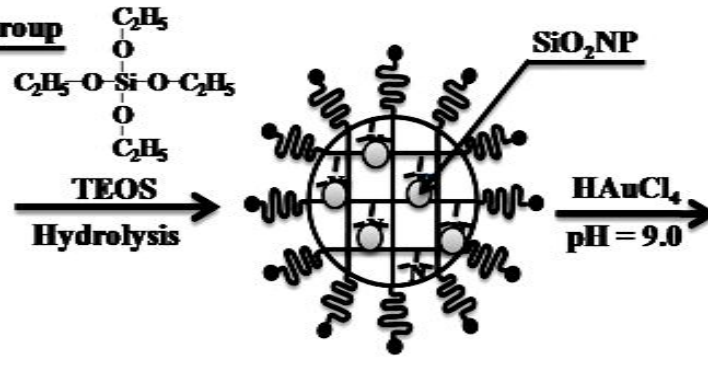

PEGylated nanogel containing $\mathrm{SiO}_{2} \mathrm{NPs}$
PEG Chain

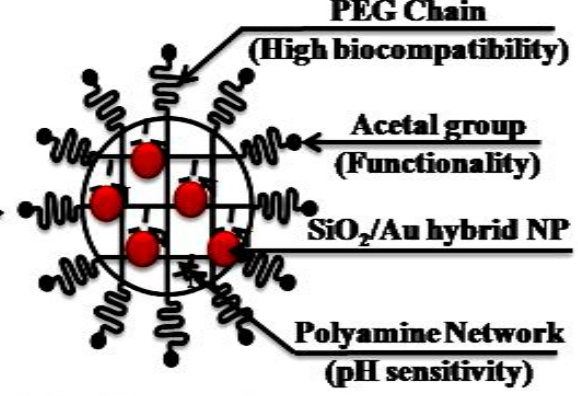

PEGylated nanogel containing

$\mathrm{SiO}_{2} / \mathrm{Au}$ hybrid NPs

Figure 2:

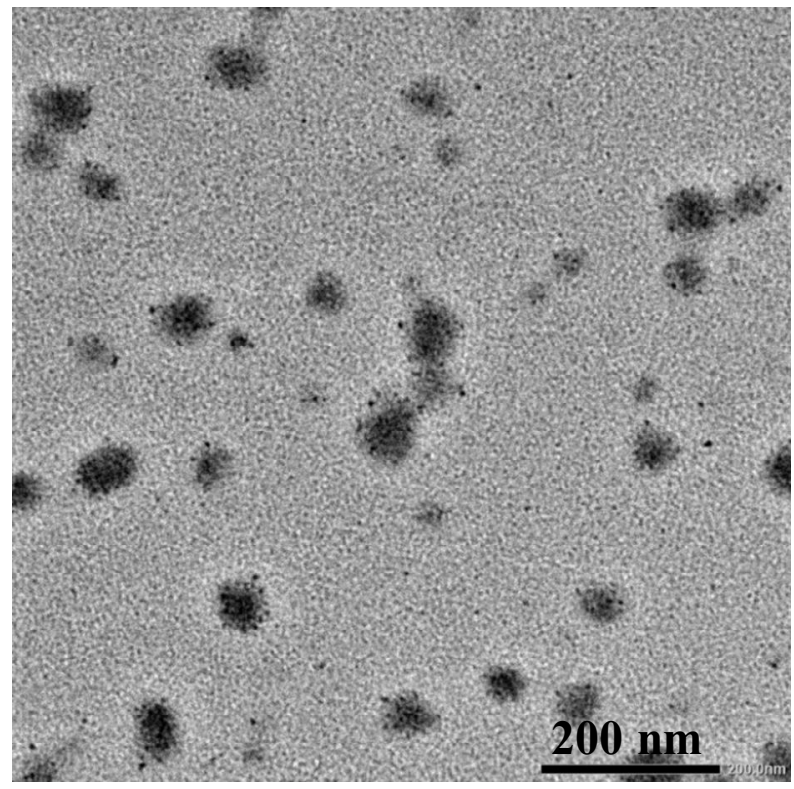


Figure 3:

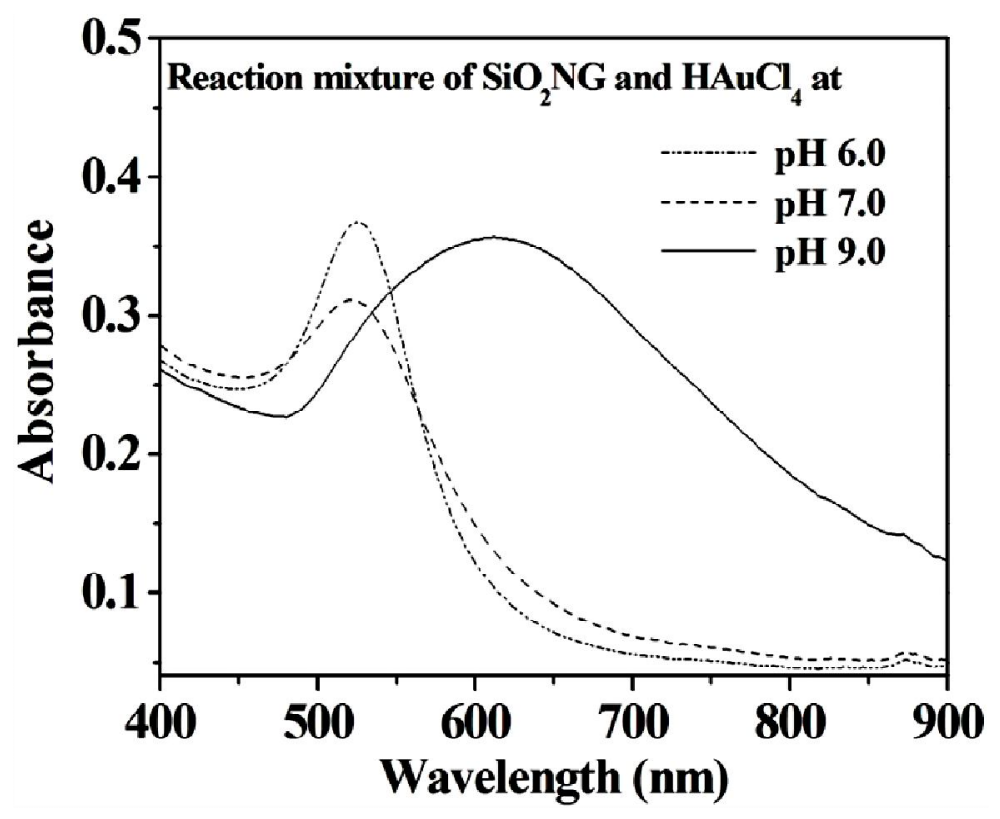

Figure 4:
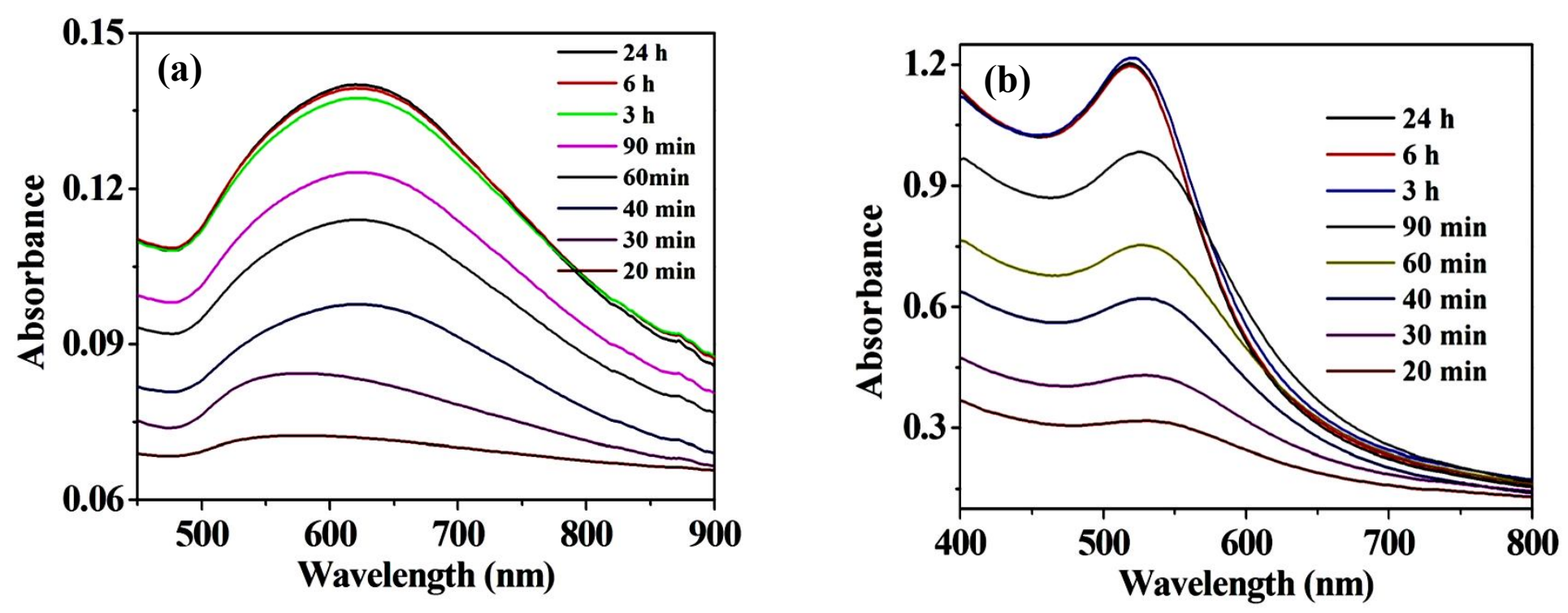
Figure 5:
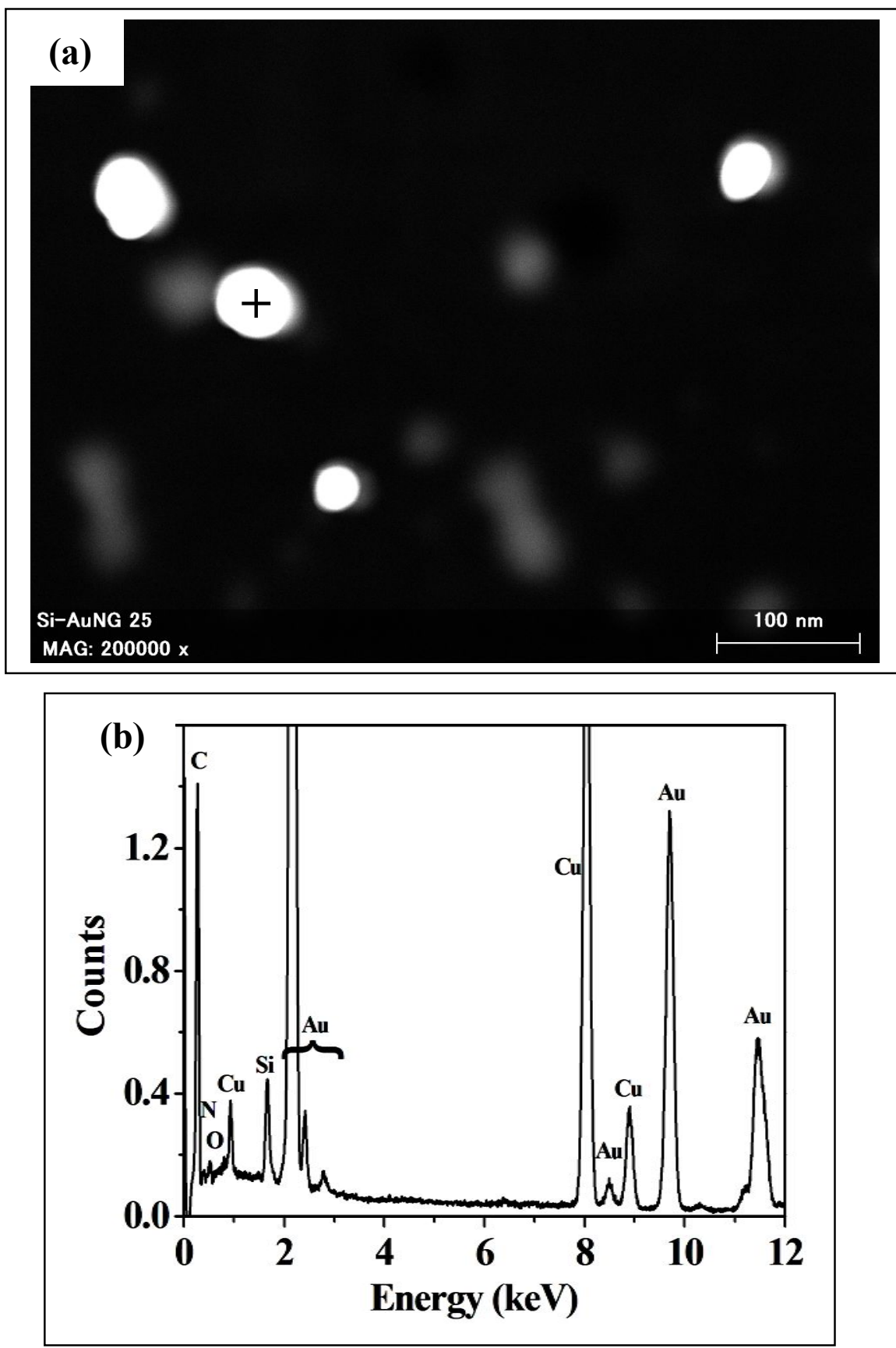
Figure 6:

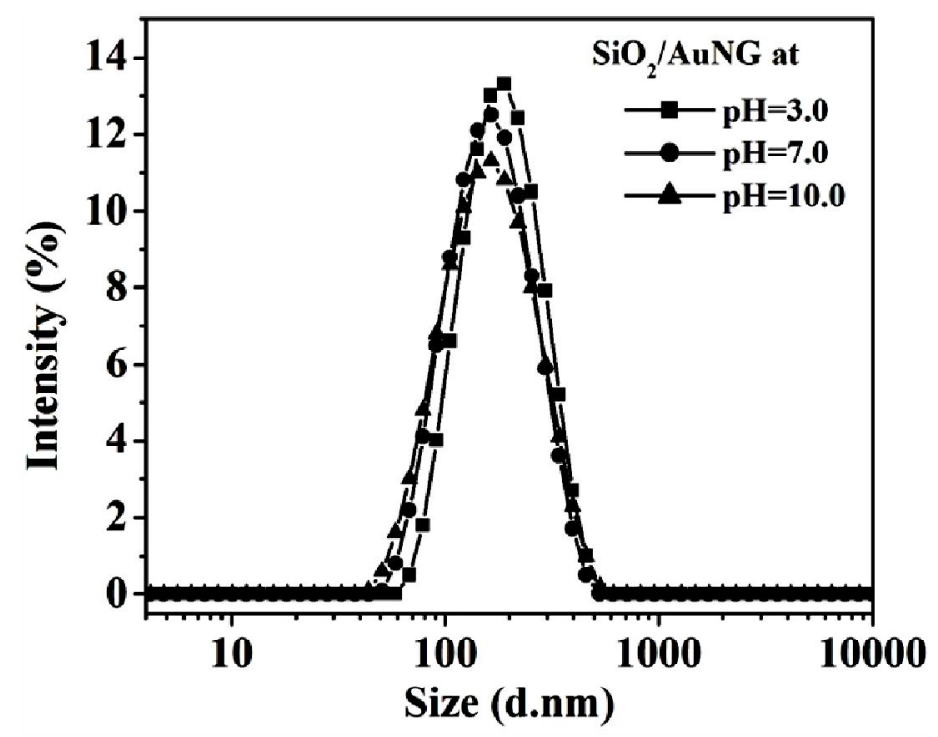

Figure 7:

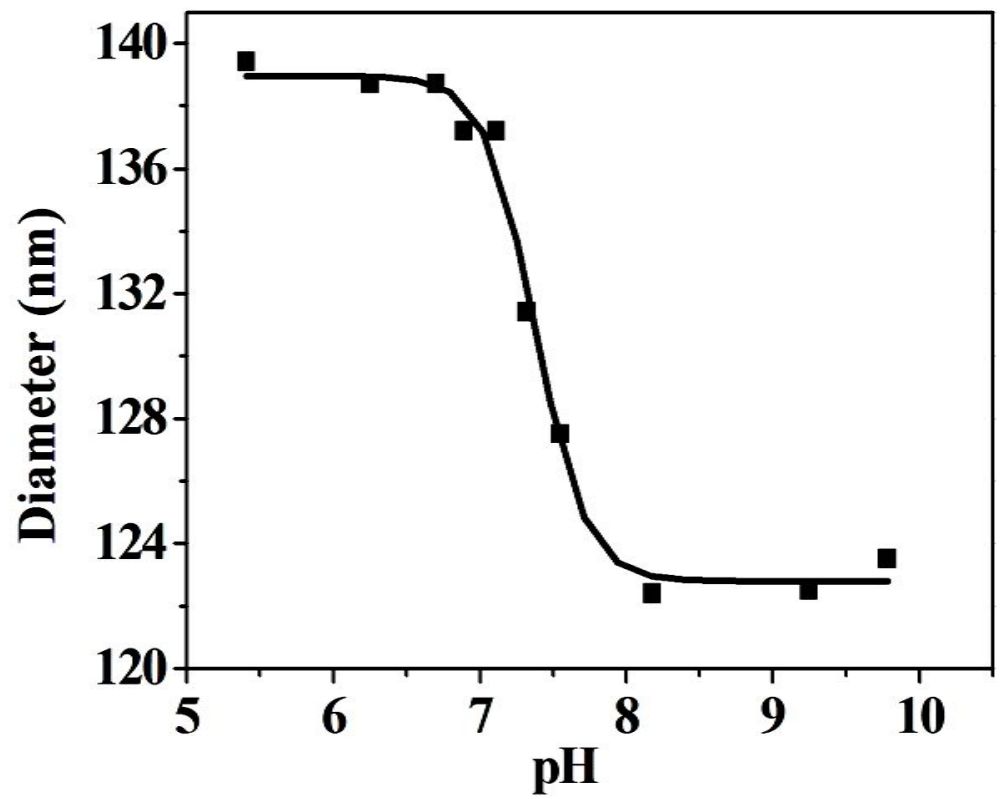


